\title{
Differentiation of Free-Living Anabaena and Nostoc Cyanobacteria on the Basis of Fatty Acid Composition
}

\author{
RODULIO CAUDALES ${ }^{1 *}$ AND JOHN M. WELLS ${ }^{2}$ \\ Department of Biochemistry and Microbiology, Lipman Hall, Cook College, Rutgers University, \\ New Brunswick, New Jersey 08903-0231, ${ }^{1}$ and Eastern Regional Research Center, \\ U.S. Department of Agriculture, Philadelphia, Pennsylvania $19118^{2}$
}

\begin{abstract}
The cellular fatty acids of free-living, nitrogen-fixing cyanobacteria belonging to the genera Anabaena and Nostoc were analyzed to differentiate the genera. The fatty acid compositions of 10 Anabaena strains and 10 Nostoc strains that were grown for 12 days on BG-11 ${ }_{0}$ medium were determined by gas-liquid chromatography-mass spectroscopy. Of the 53 fatty acids detected, 17 were major components; the average level for each of these 17 fatty acids was at least $0.9 \%$ of the total fatty acids (in at least one of the genera). These fatty acids included (with mean percentages in the Anabaena and Nostoc strains, respectively) the saturated fatty acids 16:0 (30.55 and $23.23 \%)$ and 18:0 (0.77 and 1.27\%); several unsaturated fatty acids, including $14: 1$ cis-7 (2.50 and $0.11 \%), 14: 1$ cis-9 $(3.10$ and $3.41 \%)$, a polyunsaturated 16-carbon (sites undetermined) fatty acid with an equivalent chain length of $15.30(1.20$ and $1.03 \%), 16: 4$ cis-4 $(0.95$ and $0.87 \%)$, 16:3 cis-6 (2.16 and $1.51 \%)$, 16:1 cis-7 (1.44 and $0.36 \%)$, 16:1 cis-9 (6.53 and 18.76\%), 16:1 trans-9 (4.02 and 1.35\%), $16: 1$ cis-11 (1.62 and $0.42 \%), 18: 2$ cis-9 $(10.16$ and $12.44 \%), 18: 3$ cis-9 $(18.19$ and $17.25 \%), 18: 1$ cis-9 $(4.01$ and 5.10\%), and $18: 1$ trans-9 $(0.92$ and $1.94 \%)$; and the branched-chain fatty acids iso-16:0 $(2.50$ and $1.14 \%)$ and iso-15:1 $(0.34$ and $\mathbf{2 . 0 5 \%}$ ). Among the fatty acids or classes of fatty acids that were significantly different in the genera Anabaena and Nostoc, and thus of taxonomic value (with ranges in the Anabaena and Nostoc strains, respectively), were 16:0 (27.39 to 34.72 and 18.50 to $26.10 \%$ ) and the total saturated, straight-chain, even-carbon fatty acids (class A) (29.06 to 36.61 and 21.06 to $28.62 \%)$; in addition, the ratios of class $C$ fatty acids (unsaturated straight-chain fatty acids) to class $A$ fatty acids were significantly different (1.52 to 2.13 and 2.25 to 3.47). On the basis of these parameters, Anabaena variabilis isolate ATCC 29413 has the fatty acid characteristics of a Nostoc strain and should be considered for reclassification as Nostoc variabilis; and strain ATCC 27895, which was originally placed in the species Anabaenopsis circularis, should be retained in the genus Nostoc.
\end{abstract}

Cyanobacteria are advanced prokaryotic organisms that have possible fossil records which date back $3.5 \times 10^{9}$ years (28) and are considered a link between prokaryotes and photosynthetic eukaryotes (19). These organisms are oxygenic, photosynthetic, gram-negative prokaryotes and presumably were responsible for conversion of the earth's atmosphere from anaerobic to aerobic and for the subsequent evolution of eukaryotic organisms (9).

Cyanobacteria are morphologically diverse, ranging from simple unicellular organisms to complex filamentous organisms. They are world-wide in distribution and are found in marine, aquatic, and terrestial environments, including arid and tropical acidic soils (6). Many cyanobacteria are symbiotically associated with plants and lichens, and they can occur intracellularly in other eukaryotic organisms (21). Members of the genera Anabaena and Nostoc are some of the most important cyanobacteria that occur in terrestrial and aquatic environments; these organisms are found as free-living forms or as cyanobionts $(6,10,21)$.

The division between the genus Anabaena and the genus Nostoc, two apparently closely related genera, is problematic because of the morphological similarities of the members of these genera. Since the first description of the genus Nostoc by Vaucher (30) and the first description of the genus Anabaena by Bory de St. Vincent (2), the correct classification of these taxa has been controversial. Specialized morphological criteria have been used to distinguish these groups, such as the (ambiguous) concept of a sheath sur-

\footnotetext{
* Corresponding author.
}

rounding the trichomes under certain conditions and the size, shape, and relative positions of vegetative cells, heterocysts, and akinetes $(8,11,15)$. Rippka et al. $(22,24)$ recently suggested that the developmental cycles should be used as the major criterion to differentiate the genus Nostoc from the genus Anabaena. Using DNA-DNA hybridization, Lachance (17) and Stulp and Stam (29) showed that there is a great deal of DNA-DNA diversity within the group. However, since many Nostoc isolates do not have a developmental cycle $(6,22)$, new and more reliable taxonomic techniques should be explored for differentiation.

The fatty acid compositions of eubacteria (18) and microalgae (1) are generally characteristic for each species, and thus fatty acid composition is a tool that can be used for identification. The major fatty acids of cells and membranes of Anabaena spp. have been described previously $(16,25$, 26). These fatty acids include the saturated fatty acids $14: 0$, $16: 0$, and 18:0 and the mono- and polyunsaturated 16-, 18-, and 20 -carbon fatty acids and some isomers, each of which accounts for $1 \%$ or more of the total fatty acids. However, there have been few recent reports of analyses of the fatty acids of cyanobacteria, particularly analyses in which gasliquid chromatography with capillary glass columns was used, which yield highly detailed chromatograms.

In this paper we show that analysis of fatty acid compositions by gas-liquid chromatography-mass spectroscopy was a rapid and reliable method for differentiating the genus Nostoc from the genus Anabaena. In addition, we found that fatty acids that have not been reported previously in these cyanobacteria are useful as taxonomic or evolutionary markers. 
TABLE 1. Strains of Anabaena and Nostoc cyanobacteria used in this study ${ }^{a}$

\begin{tabular}{|c|c|c|}
\hline Bacterium & Strain & Source $^{h}$ \\
\hline Anabaena cylindrica & PCC $7122^{\mathrm{TC}}$ & PCC \\
\hline A. dolium & UTEX 2094 & UTEX \\
\hline A. aequalis & UTEX 1609 & UTEX \\
\hline A. subcylindrica & UTEX 1617 & UTEX \\
\hline A. minutissima & UTEX 1613 & UTEX \\
\hline A. verrucosa & UTEX 1619 & UTEX \\
\hline A. sphaerica & UTEX 1616 & UTEX \\
\hline A. randawae & UTEX 1823 & UTEX \\
\hline A. catenula & UTEX 375 & UTEX \\
\hline A. inaequalis & UTEX 380 & UTEX \\
\hline A. variabilis & ATCC $29413^{d}$ & ATCC \\
\hline Nostoc sp. & ATCC 27895 & ATCC \\
\hline Nostoc foliaceum & UTEX 1624 & UTEX \\
\hline$N$. piscinale & UTEX 1628 & UTEX \\
\hline N. zetterstedtii & UTEX 1632 & UTEX \\
\hline N. muscorum & UTEX 2209 & UTEX \\
\hline Nostoc sp. & PCC 6705 & PCC \\
\hline Nostoc sp. & PCC 7906 & PCC \\
\hline Nostoc sp. & PCC $73102^{e}$ & PCC \\
\hline Nostoc sp. & N7 & Fay \\
\hline
\end{tabular}

${ }^{a}$ All of the strains which we studied are free-living bacteria.

b PCC, Pasteur Culture Collection, Institut Pasteur, Paris, France; UTEX, Botany Department, University of Texas, Austin; ATCC, American Type Culture Collection, Rockville, Md.; Fay, P. Fay, Westfield College, University of London, London, England.

$\mathrm{T}=$ type strain.

${ }^{d}$ Strain ATCC 29413 is considered a member of the genus Nostoc (23; this paper).

"This strain was originally isolated from Macrozamia sp., but is cultivable and can survive as a free-living bacterium.

\section{MATERIALS AND METHODS}

Cultivation and isolation of cyanobacteria. Free-living cyanobacteria, 10 strains of Anabaena spp. and 10 strains of Nostoc spp. (Table 1), were grown under continuous cool white fluorescent light for 12 days at $25 \pm 1^{\circ} \mathrm{C}$ in $\mathrm{BG}-11_{0}$ medium at 50 microeinsteins $\cdot \mathrm{m}^{-2} \cdot \mathrm{s}^{-1}$.

The Anabaena isolates that were selected for this study were the available strains that were classified as members of the genus Anabaena on the basis of DNA-DNA relatedness data (29). The Nostoc strains were selected randomly from previously characterized isolates belonging to established collections. Cells were harvested by centrifugation and stored at $-20^{\circ} \mathrm{C}$ until they were analyzed. Prior to harvest, each culture was examined microscopically. The cultures that showed evidence of contamination were homogenized in a blender, washed three times in BG- $11_{0}$ medium by using centrifugation at a low speed $(500 \times g)$, and then centrifuged for $20 \mathrm{~min}$ in a 10 to $90 \%$ Percoll gradient (Sigma Chemical Co., St. Louis, Mo.) at $2,500 \times g$ or at higher speeds, depending on the amount of mucilagenous material present in the preparation. The band containing cyanobacteria was harvested, washed two times in medium, and again examined microscopically for purity.

Fatty acid analysis. Approximately 400 to $500 \mathrm{mg}$ (wet weight) of cells was saponified and esterified by adding $1 \mathrm{ml}$ of $1.2 \mathrm{~N} \mathrm{NaOH}$ in $50 \%$ aqueous methanol and heating the preparation for $30 \mathrm{~min}$ in a boiling water bath; then the mixture was combined with $0.5 \mathrm{ml}$ of $6 \mathrm{~N} \mathrm{HCl}$ and $1 \mathrm{ml}$ of $12 \%$ boron trichloride-methanol and heated for $5 \mathrm{~min}$ at $85^{\circ} \mathrm{C}$. The methylated acids were then extracted with $1 \mathrm{ml}$ of hexane-diethyl ether $(1: 1)$, washed with $3 \mathrm{ml}$ of $0.3 \mathrm{~N} \mathrm{NaOH}$, and concentrated to a volume of approximately 20 to $40 \mu \mathrm{l}$.
A 2- $\mu$ l portion of a concentrated sample was injected into a Varian model 3700 gas chromatograph equipped with a flame ionization detector and a capillary glass column $(15 \mathrm{~m}$ by $0.25 \mathrm{~mm}$ ) coated with SPB-1 (Supelco, Inc.) as a nonpolar stationary phase. The operating conditions were as follows: helium carrier gas flow rate, $20 \mathrm{ml} / \mathrm{min}$; injector temperature, $230^{\circ} \mathrm{C}$; detector temperature, $250^{\circ} \mathrm{C}$; initial column temperature, $130^{\circ} \mathrm{C}$; final temperature, $230^{\circ} \mathrm{C}$; temperature program rate, $4^{\circ} \mathrm{C} / \mathrm{min}$.

Fatty acids that were between 8 and 20 carbons long were identified by cochromatographing them with reference standards. The major fatty acid peaks were confirmed with a Finnegan model $8230 \mathrm{HR}$ mass spectrometer. The identities of unsaturated fatty acids were confirmed chemically by hydrogenating methyl esters for $15 \mathrm{~min}$, as described previously $(4,20)$. Upon hydrogenation, the unsaturated acids disappeared, and corresponding increases were observed in the saturated, straight-chain analogs. The identities of hydroxy-substituted fatty acids were confirmed by trifluoroacetylation, using the method of Moss (20). After acetylation, the retention times of the diacyl derivatives of these acids shifted when they were chromatographed. The identities of cyclopropane fatty acids were confirmed by hydrogenating and brominating methyl esters, and the cyclopropane fatty acids were rechromatographed on Chromosorb W coated with $20 \%$ diethylene glycol succinate (Supelco, Inc.) as described by Bryan and Gardner (3). Known 17:0 and 19:0 cyclic fatty acids (Supelco, Inc., and Applied Science, State College, Pa.) were used as internal standards. The carbon equivalent chain length (ECL) was calculated for each peak to provide further confirmation of the identity of the compound by reference to previously published reports (12).

\section{RESULTS}

The cellular fatty acids of the free-living Nostoc and Anabaena isolates included 17 major components; the average level of each of these components (in at least one of the genera) was $0.9 \%$ or more of the total fatty acids. There were also 26 minor components (average level, at least $0.03 \%$ of the total fatty acids) and 10 trace level components (average level, $0.03 \%$ or less) (Table 2). The major fatty acids included the saturated, even-carbon, straight-chain (class A) fatty acids 16:0 and 18:0; unsaturated straight-chain fatty acids (class C), including 14:1 cis-7, 14:1 cis-9, seven unsaturated 16-carbon fatty acids (subtotals, 17.92 and $24.30 \%$ for Anabaena spp. and Nostoc spp., respectively), and four unsaturated 18 -carbon fatty acids ( 34.44 and $37.26 \%$, respectively); the saturated branched-chain (class E) fatty acid iso-16:0; and the unsaturated branched-chain (class G) fatty acid iso-15:1. The largest single component was 16:0; the values for this fatty acid characteristically were high for Anabaena isolates (range, 27.39 to $34.72 \%$ ) and low for Nostoc isolates (range, 18.50 to $26.10 \%$ ).

Among the minor components $(0.03 \%$ or more of the total fatty acids in at least one of the genera) were the polyunsaturated fatty acids 12:1 cis-7 (ECL 11.8), 16:4 (ECL 15.2), 18:3 cis-6 (ECL 17.2), 18:4 cis-6 (ECL 17.5), 20:4 cis-5 (ECL 19.2), 20:4 cis-8 (ECL 19.4), and 20:2 cis-11 (ECL 19.7). These fatty acids contributed to the largest class of fatty acids in cyanobacteria, the unsaturated straight-chain fatty acids (class C) (range 55.72 to $73.20 \%$ of the total fatty acids).

The lowest averages in the fatty acid profiles of the cyanobacteria were obtained for the hydroxy-substituted fatty acids (class D) and the cyclopropane acids (class F). 
TABLE 2. Cellular fatty acids and mean percentages of the total fatty acids for 10 strains of free-living Anabaena and Nostoc cyanobacteria

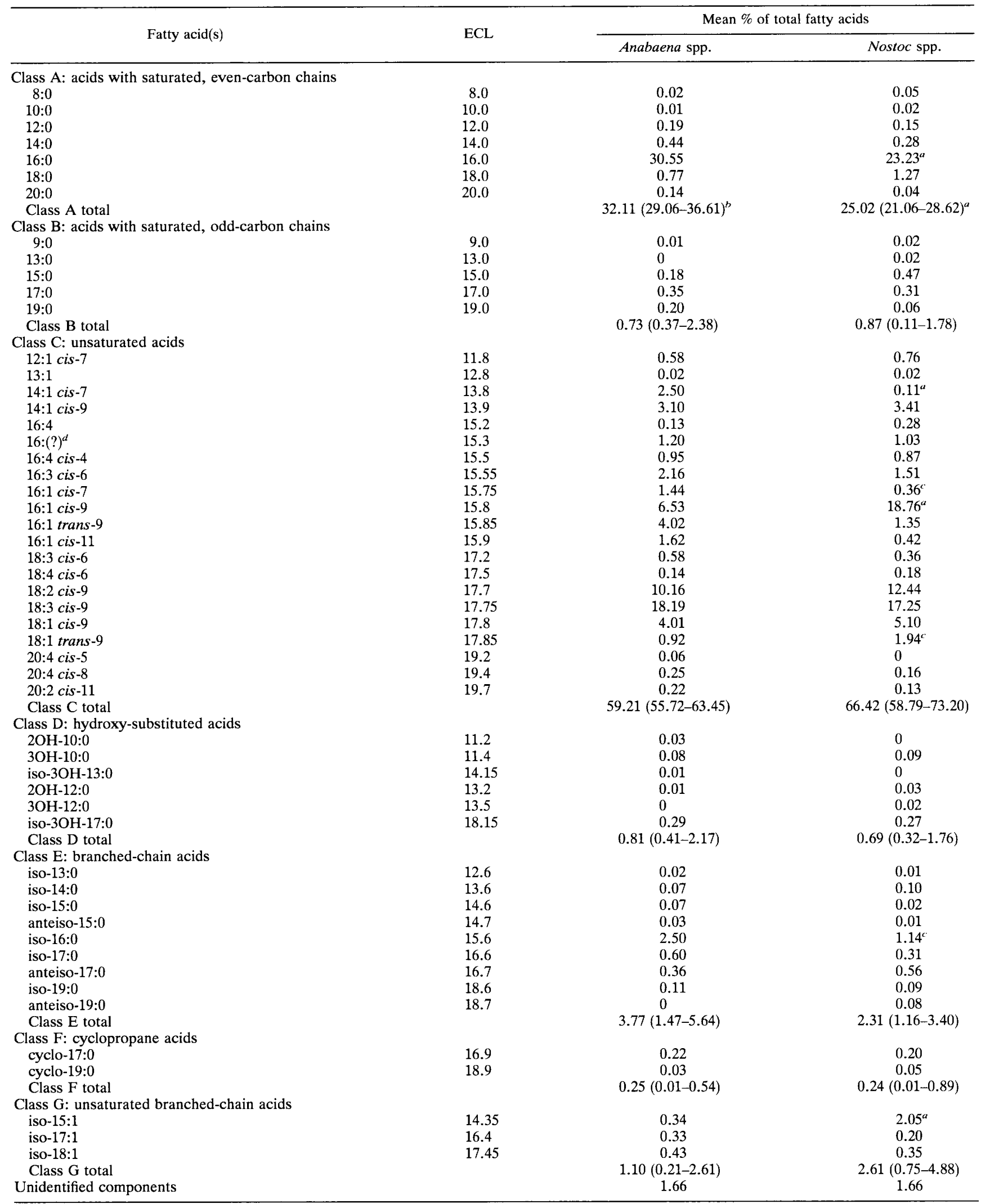

${ }^{a}$ Mean was significantly different from the mean for Anabaena spp. as determined by the least significant difference test $(P \geq 0.05)$.

$b$ The values in parentheses are ranges.

${ }^{c}$ Mean was significantly different from the mean for Anabaena spp. $(P \geq 0.10)$.

${ }^{d}$ Unsaturated sites not determined. 
TABLE 3. Percentages and ratios of selected fatty acids and classes that are useful for differentiating isolates of Anabaena and Nostoc spp.

\begin{tabular}{|c|c|c|c|c|c|c|c|}
\hline \multirow{2}{*}{ Bacterium } & \multirow{2}{*}{ Strain } & \multicolumn{5}{|c|}{$\%$ of total fatty acids } & \multirow{2}{*}{$\begin{array}{l}\text { Ratio of } \\
\text { class C fatty } \\
\text { acids to class } \\
\text { A fatty } \\
\text { acids }^{a}\end{array}$} \\
\hline & & $14: 1$ cis -7 & iso-15:1 & $16: 1$ cis -9 & $16: 0$ & $\begin{array}{l}\text { Class A fatty } \\
\text { acids }\end{array}$ & \\
\hline A. cylindrica & PCC 7122 & 4.47 & 0.38 & 3.85 & 32.16 & 33.26 & 1.73 \\
\hline A. dolium & UTEX 2094 & 0.28 & 0 & 15.02 & 29.95 & 31.88 & 1.67 \\
\hline A. aequalis & UTEX 1609 & 4.56 & 0 & 3.86 & 32.01 & 33.96 & 1.75 \\
\hline A. subcylindrica & UTEX 1617 & 5.31 & 0.08 & 3.53 & 27.98 & 29.10 & 2.11 \\
\hline A. minutissima & UTEX 1613 & 2.05 & 0.07 & 10.31 & 29.14 & 30.03 & 2.11 \\
\hline$A$. verrucosa & UTEX 1619 & 3.11 & 0.02 & 4.15 & 32.28 & 33.92 & 1.75 \\
\hline A. sphaerica & UTEX 1616 & 0 & 2.13 & 4.70 & 27.39 & 29.06 & 2.13 \\
\hline A. randawae & UTEX 1823 & 0.01 & 0.23 & 14.00 & 34.72 & 36.61 & 1.52 \\
\hline A. catenula & UTEX 375 & 2.48 & 0 & 2.67 & 29.34 & 30.54 & 2.05 \\
\hline A. inaequalis & UTEX 380 & 2.77 & 0.20 & 3.22 & 30.50 & 32.76 & 1.75 \\
\hline $\begin{array}{c}\text { Anabaena spp. } \\
\text { mean } \pm \text { SD }\end{array}$ & & $2.50 \pm 1.94$ & $0.34 \pm 0.64$ & $6.53 \pm 4.72$ & $30.55 \pm 2.30$ & $32.11 \pm 2.45$ & $1.84 \pm 0.22$ \\
\hline A. variabilis & ATCC 29413 & 0 & 1.81 & 21.22 & 22.54 & 23.80 & 2.79 \\
\hline Nostoc sp. & ATCC 27895 & 0.12 & 0.88 & 27.82 & 22.36 & 23.75 & 3.02 \\
\hline$N$. foliaceum & UTEX 1624 & 0.62 & 2.33 & 13.96 & 23.97 & 25.21 & 2.52 \\
\hline$N$. piscinale & UTEX 1628 & 0 & 1.94 & 19.61 & 23.74 & 25.90 & 2.58 \\
\hline N. zetterstedtii & UTEX 1632 & 0 & 4.74 & 14.38 & 25.32 & 27.17 & 2.34 \\
\hline N. muscorum & UTEX 2209 & 0.06 & 0.65 & 21.26 & 25.01 & 25.52 & 2.69 \\
\hline Nostoc sp. & PCC 6705 & 0 & 4.20 & 21.41 & 21.71 & 23.20 & 2.89 \\
\hline Nostoc sp. & PCC 7906 & 0 & 2.52 & 12.77 & 23.07 & 25.97 & 2.26 \\
\hline Nostoc sp. & PCC 73102 & 0.33 & 0 & 14.63 & 26.10 & 28.62 & 2.25 \\
\hline Nostoc sp. & N7 & 0 & 1.47 & 20.52 & 18.5 & 21.06 & 3.47 \\
\hline $\begin{array}{l}\text { Nostoc spp. } \\
\text { mean } \pm \text { SD }\end{array}$ & & $0.11 \pm 0.21^{b}$ & $2.05 \pm 1.49^{b}$ & $18.76 \pm 4.72^{b}$ & $23.23 \pm 2.17^{b}$ & $25.02 \pm 2.15^{b}$ & $2.68 \pm 0.38$ \\
\hline
\end{tabular}

a The class A fatty acids were the saturated, even-carbon, straight-chain fatty acids; the class $\mathrm{C}$ fatty acids were the unsaturated, straight-chain fatty acids.

${ }^{b}$ Mean was significantly different from the mean for Anabaena spp. $(P \geq 0.05)$.

Many individual constituents were detected at trace levels (close to the limits of column resolution), but their presence was confirmed chemically.

The most useful factors for differentiating the two groups of cyanobacteria, in addition to the percentages of 16:0, were the class A fatty acids. The ranges of class A fatty acid levels for the Anabaena isolates and the Nostoc isolates were 29.06 to 36.61 and 21.06 to $28.62 \%$, respectively (Table 3 ). The ratios of unsaturated fatty acids (class C) to saturated fatty acids (class $\mathrm{A}$ ) were also significantly different in the two genera; there was no overlapping of ranges (1.52 to 2.13 for Anabaena isolates and 2.25 to 3.47 for Nostoc isolates), and the standard deviations were low. Three unsaturated fatty acids, 14:1 cis $-7,16: 1$ cis -9 , and iso-15:1, were also valuable for differentiation, as their percentages in the two genera were statistically different at the $95 \%$ level of probability.

\section{DISCUSSION}

The cyanobacterial genera Anabaena and Nostoc can be differentiated on the basis of cellular fatty acids. However, our analysis differed in some respects from the analyses performed by other investigators $(16,25,26)$. The most obvious difference was our use of several chemical classes of fatty acids that have not been used previously for the genera Anabaena or Nostoc, including saturated odd-carbon, hydroxy-substituted, branched-chain, cyclopropane, and unsaturated branched-chain fatty acids. These classes account for $6.8 \%$ of the total fatty acids. Other differences were our higher values for 16:0 (average in Anabaena isolates, $30.55 \%$ ) compared with previously published values (18.3 to $23.2 \%$ ), and our lower totals for unsaturated fatty acid contents $(59.21 \%$, compared with at least $76 \%$ in all other reports $[16,25,26])$. These differences resulted in significantly dissimilar ratios of saturated fatty acids (classes A and B) to unsaturated fatty acids (class C) ( 0.56 for our data and less than 0.3 for data in other reports).

Many of these discrepancies may be explained by differences in experimental conditions. Cells in other studies were cultured at $38^{\circ} \mathrm{C}$ and in atmospheres enriched with carbon dioxide and were harvested generally at the log phase of growth. In our study, cells were grown in air at $25^{\circ} \mathrm{C}$ and were harvested at the late log phase. Regarding illumination, Sato and Murata (27) showed that high illumination during growth stimulated the desaturation of $18: 1$ to $18: 2$ and the desaturation of $18: 2$ to $18: 3$ in "Anabaena variabilis" (27). Thus, our lower levels of unsaturated fatty acids could be attributed in part to lower illumination levels. High temperatures, such as those used in the other studies, also induce desaturation of 16:0, 18:1, and 18:2 (27).

Fatty acid composition can also be affected by differentiation of vegetative cells (into heterocysts, akinetes, and hormogonia), by physiological age, and by growth conditions that are either photoautotrophic, mixed, or heterotrophic (6). Thus, in order to obtain reproducible data, samples to be compared should be grown under the same environmental conditions and in the same medium and be at comparable physiological ages.

Significant taxonomic distinctions between groups of bacteria are generally reflected in the composition of cellular fatty acids (18). This is true of Anabaena and Nostoc isolates, in which basic compositional differences could be demonstrated, particularly in the physiologically important ratios of saturated fatty acids to unsaturated fatty acids. A rapid key for differentiation would be the percentage of 16:0 
(more than $27 \%$ for Anabaena spp. and less than $27 \%$ for Nostoc spp.). These data are in agreement with the results of other workers $(16,25,26)$, who found that the values reported for $16: 0$ (18.0 to $20.4 \%$ ) in isolates that were originally identified or subsequently reclassified as Nostoc spp. (24) were consistent with such a separation. In addition, a more stringent algorithm for separation of the genera Anabaena and Nostoc, and perhaps separation of strains within the groups, may be constructed from our data by combining all of the factors that are significantly different, including the levels of $14: 1 \mathrm{cis}-7$, iso-15:1, and 16:1 cis-9. Such an algorithm may be the percentage of 16:0 divided by the ratio of class $C$ fatty acids to class $A$ fatty acids and may assist in the segregation of larger groups of isolates.

A practical ramification of this analysis is the prospect of rapid screening of Nostoc and Anabaena isolates prior to detailed morphological studies, particularly since hormogonia are not always formed in Nostoc spp. $(6,22)$. Furthermore, fatty acid profiles of representatives of all five orders of cyanobacteria might be developed for rapid identification. Of equal significance is the possibility that precise fatty acid profiles might be used to confirm identifications made on the basis of morphological criteria.

Our isolate of Anabaena variabilis, strain ATTC 29413 (= PCC $7937=$ UTEX 1444), had a fatty acid profile that is typical of Nostoc spp., as shown in Table 3; the level of 16:0 was $22.54 \%$ of the total fatty acids, the level of all class A fatty acids was $23.8 \%$, and the ratio of class $\mathrm{C}$ fatty acids to class A fatty acids was 2.79 . These parameters confirm that this cyanobacterium is a typical Nostoc isolate. Furthermore, Anabaena variabilis produces hormogonia, a morphological feature that is typical of Nostoc spp. (23). On the basis of the developmental cycle and fatty acid profile, we suggest that this organism should be reclassified as Nostoc variabilis.

Another problematic isolate was Nostoc sp. strain ATCC 27895 (= PCC 6720), which was originally identified as Anabaenopsis circularis (31) and was placed in the genus Nostoc by Rippka et al. (24) on the basis of its life cycle. Castenholz placed this organism in the genus Anabaena as a result of a reclassification of the genus Anabaenopsis (5). However, fatty acid composition (16:0, 22.36\%; class A fatty acids, $23.75 \%$; ratio of class $\mathrm{C}$ fatty acids to class A fatty acids, 3.02) placed it in the genus Nostoc rather than the genus Anabaena, in agreement with Rippka et al. (24). We suggest that the entire Anabaenopsis group should be reexamined member by member to confirm the proper classification of these organisms.

Polyunsaturated fatty acids have been considered to be rare or absent in prokaryotic bacteria. However, in the oxygenic photosynthesizing members of the genera Nostoc and Anabaena, the polyunsaturated fatty acids $18: 2$ and 18:3 are predominant constituents, as they are in chloroplasts of algae and higher plants (13). The polyunsaturated fatty acids $20: 2$ and $20: 4$ are also present in smaller quantities in Anabaena and Nostoc isolates. The only other bacterial groups that have been reported to contain polyunsaturated fatty acids are Flexibacter sp. (14) and Vibrio marinus (7).

Fatty acid analysis is a valuable chemotaxonomic tool, as shown by the differentiation of the genera Anabaena and Nostoc. The fatty acid composition and relative percentages of individual components in each genus could reflect evolutionary changes and metabolic and biochemical processes in cyanobacteria.

\section{ACKNOWLEDGMENTS}

We acknowledge the contributions of R. Rippka for providing some Pasteur Culture Collection isolates of cyanobacteria and of J. A. Zeikus (Botany Department, University of Texas) for facilitating the transfer of cultures. We thank L. G. Revear and J. Butterfield of the U.S. Department of Agriculture for their work on the analysis and computerization of the fatty acid data reported in this paper. We also thank Peter E. Smouse (Rutgers University), William J. Zimmerman (University of Michigan at Dearborn), and Robert Moreau (U.S. Department of Agriculture, Philadelphia, Pa.) for critically reading the manuscript.

\section{REFERENCES}

1. Ben-Amotz, A., T. G. Tornabene, and W. H. Thomas. 1985. Chemical profile of selected species of microalgae with emphasis on lipids. J. Phycol. 21:72-81.

2. Bory de St. Vincent, J. B. 1822. Anabaena, p. 307. In Dictionnaire classique d'historie naturelle, vol. 1. Rey, Gravier and Baudoin Frerès, Paris.

3. Bryan, L. B., and E. W. Gardner. 1968. A simple procedure for detecting the presence of cyclopropane fatty acids in bacterial lipids. Appl. Microbiol. 16:549-552.

4. Casano, F., J. Wells, and T. Van Der Zwet. 1988. Fatty acid profiles of Erwinia amylovora as influenced by growth medium, physiological age and experimental conditions. J. Phytopathol. 121:267-274.

5. Castenholz, R. W. 1989. Family I. Nostocaceae, p. 1783. In R. E. Buchanan and N. E. Gibbons (ed.), Bergey's manual of systematic bacteriology, vol. 3 . The Williams \& Wilkins Co., Baltimore.

6. Caudales, R., and J. M. Wells. Unpublished data.

7. DeLong, E. F., and A. A. Yayanos. 1986. Biochemical function and ecological significance of novel bacterial lipids in deep sea procaryotes. Appl. Environ. Microbiol. 51:730-737.

8. Desikachary, T. V. 1959. Cyanophyta. Indian Council of Agricultural Research, New Delhi, India.

9. Doolittle, W. F. 1982. Molecular evolution, p. 307-332. In N. G. Carr and B. A. Whitton (ed.), The biology of cyanobacteria. Bot. Monogr., vol. 19. University of California Press, Berkeley.

10. Fogg, G. E., W. D. P. Steward, P. Fay, and E. Walsby. 1973. The blue-green algae, p. 311-342. Academic Press, New York.

11. Geitle, L. 1932. Cyanophyceae, p. 827-869. In R. Kolkwitz (ed.), Rabenhorst's Kryptogamenflora von Deutschland, Österreich und der Schweiz, vol. 14. Akademische Verlagsgesellschaft, Leipzig, Germany.

12. Gillan, F. T., and R. W. Hogg. 1984. A method for the estimation of bacterial biomass and community structure in mangrove-associated sediments. J. Microbiol. Methods 2:275293.

13. Golecki, J. R., and G. Drews. 1982. Supramolecular organization and composition of membranes, p. 125-141. In N. G. Carr and B. A. Whitton (ed.), The biology of cyanobacteria. Bot. Monogr., vol. 19. University of California Press, Berkeley.

14. Johns, R. B., and G. J. Perry. 1977. Lipids of the marine bacterium Flexibacter polymorphus. Arch. Microbiol. 114:267671.

15. Kantz, T., and H. C. Bold. 1969. Phycological studies. IX. Morphological and taxonomic investigations of Nostoc and Anabaena in culture. Publication no. 6924. University of Texas, Austin.

16. Kenyon, C. N., R. Rippka, and R. Y. Stanier. 1972. Fatty acid composition and physiological properties of some filamentous blue-green algae. Arch. Mikrobiol. 83:216-236.

17. Lachance, M. A. 1980 . Genetic relatedness of heterocystous cyanobacteria by deoxyribonucleic acid-deoxyribonucleic acid reassociation. Int. J. Syst. Bacteriol. 31:139.

18. Lechevalier, M. P. 1977. Lipids in bacterial taxonomy-a taxonomist's view. Crit. Rev. Microbiol. 5:109-210.

19. Margulis, L., J. Walker, and M. Rambler. 1976. Reassessment of roles of oxygen and ultraviolet light in Precambrian evolution. Nature (London) 264:620-624.

20. Moss, C. W. 1979. Analysis of cellular fatty acids of bacteria by gas-liquid chromatography, p. 117-122. In G. L. Jones and 
G. A. Herbert (ed.), "Legionnaires," the disease, bacteria and methodology. U.S. Department of Health, Education and Welfare, Atlanta.

21. Rai, A. M. 1990. Cyanobacteria in symbiosis, p. 1-7. In A. N. Rai (ed.), Handbook of symbiotic cyanobacteria. CRC Press, Boca Raton, Fla.

22. Rippka, R. 1988. Recognition and identification of cyanobacteria. Methods Enzymol. 167:28-67.

23. Rippka, R. (Pasteur Institute). 1990. Personal communication.

24. Rippka, R., J. Deruelles, J. B. Waterbury, M. Herdman, and R. Y. Stanier. 1979. Genetic assignments, strain histories and properties of pure cultures of cyanobacteria. J. Gen. Microbiol. 111:1-61.

25. Sandmann, G., and P. Boger. 1982. Volatile hydrocarbons from photosynthetic membranes containing different fatty acids. Lipids 17:35-41.

26. Sato, N., and N. Murata. 1981. Studies on the temperature shift-induced desaturation of fatty acids in monogalactosyl diacylglycerol in blue-green algae (cyanobacterium), Anabaena variabilis. Plant Cell Physiol. 22:1043-1050.

27. Sato, N., and N. Murata. 1988. Membrane lipids. Methods Enzymol. 167:251-259.

28. Schopf, W., and B. Packer. 1987. Early Archaean (3.3 billion- to 3.5 billion-years old) microfossils from the Warrawoona Group, Australia. Science 237:70-73.

29. Stulp, B. K., and W. T. Stam. 1984. Genotypic relationships between strains of Anabaena (Cyanophyceae) and their correlation with morphological affinities. Br. Phycol. J. 19:287-301.

30. Vaucher, J. P. 1803. Histoire des Trémelles, p. 203. In Histoire des Conferves d'Eau Deuce. J. J. Paschoud, Geneva.

31. Watanabe, A. 1959. Distribution of nitrogen-fixing blue-green algae in various areas of South and East Asia. J. Gen. Appl. Microbiol. 5:21-29. 